\title{
PERANCANGAN INFOGRAFIS MUSEUM TOKOH PAHLAWAN DI JAKARTA SEBAGAI MUSEUM ARKEOLOGI DAN SEJARAH
}

\author{
Hedi Hidayat, Muhammad Iqbal Qeis, Rina Wahyu Winarni \\ Program Studi Desain Komunikasi Visual \\ Fakultas Bahasa Dan Seni, Universitas Indraprasta PGRI \\ qeis.mi@unindra.ac.id
}

\begin{abstract}
Abstrak
Museum merupakan suatu lembaga yang bersifat tetap, tidak mencari keuntungan dan melayani kebutuhan publik melalui usaha pengkoleksian dan memamerkan benda-benda serta aset-aset bersejarah dan sumber pengetahuan bagi masyarakat. Pada tahun 2015, jumlah museum berdasarkan jenis dan kota administrasinya berjumlah 70 museum. Salah satunya yaitu museum yang bertemakan tokoh pahlawan seperti Museum Fatahillah, Museum M.H. Thamrin, Museum Sasmitaloka Ahmad Yani, dan Museum Sasmitaloka Jenderal Besar Dr. A.H. Nasution. Namun, saat ini minat masyarakat untuk mengunjungi wisata sejarah seperti museum justru masih sangat kurang. Masyarakat menganggap tempat wisata yang satu ini sebagai tempat yang membosankan yang hanya menyimpan benda-benda kuno dan terkesan menyeramkan. Selain itu juga, kurangnya media informasi terhadap museummuseum tokoh pahlawan yang ada di Jakarta membuat museum tersebut masih belum banyak diketahui oleh masyarakat luas. Penelitian ini bertujuan untuk merancang infografis museum tokoh pahlawan di Jakarta sebagai museum arkeologi dan sejarah menggunakan metode penelitian kualitatif. Hasil penelitian berupa rancangan infografis dinamis dengan durasi tayang 4 menit 43 detik dengan menggunakan gaya visual flat design. Perancangan infografis ini memiliki implikasi munculnya media informasi mengenai museum tokoh pahlawan di Jakarta yang dapat menambah pengetahuan masyarakat serta menarik minat masyarakat untuk mengunjunginya.
\end{abstract}

Kata kunci : Perancangan, Infografis, Museum, Tokoh Pahlawan, Jakarta

\begin{abstract}
Museum is a non-profit, permanent institution that aims to serve public needs through an effort to collect and display objects, historic assets, and sources of knowledge for the community. In 2015, Jakarta has approximately 70 consisted of different type of museums. One of them is a national hero museum (museum pahlawan) such as the Fatahillah Museum, the Museum of M.H. Thamrin, Ahmad Yani Museum, and Dr. AH. Nasution Museum. However, the public interest in visiting historical tourism such as museums is still very lacking nowadays. People consider museum as a boring place that only keeps ancient objects and has a creepy vibe. In addition, the lack of information media for national hero museum in Jakarta makes the museum still not widely known by the public. This study aims to design an infographics of national hero museum in Jakarta as an archaeological and historical museum using qualitative research method. The result is a design of dynamic infographics with a duration of 4 minutes 43 seconds using flat design visual style. The design of this infographic has an implication of the emergence of information media about national hero museum in Jakarta that can increase public knowledge and attract the public to visit the museum.
\end{abstract}

Keywords : Design, Infografics, Museum, National Hero, Jakarta.

\section{PENDAHULUAN}

Jakarta memiliki banyak sekali kebudayaan yang meliputi aneka warisan sejarah sebagai perpaduan antar suku dan bangsa. Warisan kebudayaan di Jakarta dapat dilihat dari berbagai aspek, seperti dari bangunan-bangunan bersejarah, hasil kebudayaan, dan keseniannya. Potensipotensi wisatanya pun banyak dan bervariasi, mulai dari wisata hiburan dan pusat perbelanjaan 
yang saat ini terus berkembang, wisata alam, sampai wisata sejarah. Sayangnya, saat ini masyarakat di kota besar justru lebih banyak memilih untuk bejalan-jalan di area pertokoan, sedangkan pada kenyataanya kegiatan wisata dapat pula diarahkan ke lokasi-lokasi bersejarah yang mengandung nilai-nilai edukasi serta wawasan seperti museum (Destha, 2016: 2)

Museum merupakan suatu lembaga yang bersifat tetap, tidak mencari keuntungan dan melayani kebutuhan publik melalui usaha pengkoleksian dan memamerkan benda-benda serta aset-aset bersejarah dan sumber pengetahuan bagi masyarakat. Museum merupakan sutau tempat penyimpanan benda-benda ber-sejarah. Keberadaan museum dimaksud-kan agar masyarakat dapat melihat, mengamati, dan mempelajari benda-benda peninggalan yang terdapat di museum. Sehingga nilai-nilai bersejarah yang terdapat pada benda-benda peninggalan itu pun dapat dilestarikan. Pada tahun 2015, jumlah museum berdasarkan jenis dan kota administrasi-nya berjumlah 70 museum (BPS Provinsi DKI Jakarta, 2016: 143). Salah satunya yaitu museum tokoh pahlawan seperti Museum Fatahillah, Museum M.H. Thamrin, Museum Sasmitaloka Ahmad Yani, dan Museum Sasmitaloka Jenderal Besar Dr. A.H. Nasution (Pemda DKI Jakarta, 2004). Nama-nama museum tersebut merupakan nama dari tokoh pahlawan nasional yang diabadikan karena telah berjasa dan berjuang demi kemerdekaan serta mempertahankan ideologi pancasila sebagai dasar Negara Republik Indonesia.

Namun, di era modernisasi seperti saat ini minat masyarakat untuk me-ngunjungi wisata sejarah seperti museum justru masih sangat kurang. Masyarakat menganggap tempat wisata yang satu ini sebagai tempat yang membosankan yang hanya menyimpan benda-benda kuno dan terkesan menyeramkan (Dimyati, 2010: 4). Kurangnya minat masyarakat Jakarta pada museum dapat dilihat dari data jumlah pengunjung yang didapatkan dari tiap-tiap museum tokoh pahlawan. Salah satu contohnya adalah museum M.H. Thamrin dengan jumlah kunjungan paling sedikit dibandingkan dengan museum tokoh pahlawan lainnya. Pada tahun 2016 saja, jumlah kunjungan hanya mencapai 1.282 orang (wawancara kepada Unit Pengelola Museum Kesejarahan Jakarta).

Selain itu juga, kurangnya media informasi terhadap museum-museum tokoh pahlawan yang ada di Jakarta membuat museum tersebut masih banyak yang belum diketahui oleh masyarakat luas terutama masyarakat kota Jakarta itu sendiri. Hal tersebut berujung pada sepinya pengunjung dan kurang diminatinya museum sebagai objek wisata bertema-kan arkeologi dan sejarah. Hal tersebut diperkuat dengan hasil observasi ke museum tokoh pahlawan di Jakarta pada tanggal 20 Maret 2018 yang mem-perlihatkan bahwasannya media pengenalan yang digunakan oleh unit pengelola museum di Jakarta masih berupa brosur dan kampanye museum ke sekolah-sekolah.

Maka dari itu, untuk mengatasi permasalahan tersebut dianggap perlu adanya media pengenalan baru mengenai museum tokoh pahlawan di Jakarta. Penelitian ini bertujuan untuk merancang infografis museum tokoh pahlawan di Jakarta sebagai museum arkeologi dan sejarah yang berisikan sejarah dan hal-hal menarik yang ada di museum tokoh pahlawan. Dengan menggunakan media infografis, dapat memudahkan dalam penyampaian informasi atau secara cepat dan jelas mengenai museum tokoh pahlawan di Jakarta kepada masyarakat luas, khususnya masyarakat kota Jakarta, serta dapat menarik minat masyarakat untuk mengunjungi museum tokoh pahlawan di Jakarta.

\section{METODE PENELITIAN}

Penelitian untuk merancang Infografis Museum Tokoh Pahlawan di Jakarta mulai dilakukan pada bulan Juli 2017 sampai Agustus 2018. Penelitian dilakukan dengan cara mengumpulkan data-data literatur dan meninjau karya yang berkaitan dengan penelitian serta 
melakukan wawancara dengan narasumber yang berperan sebagai sejarawan, maupun pihak pengelola museum tokoh pahlawan itu sendiri. Selama penelitian berlangsung, penelitian dilakukan di museum tokoh pahlawan seperti Museum Fatahillah (Jakarta Utara), Museum M.H. Thamrin, Museum Jenderal Besar Dr. A.H. Nasution dan Museum Sasmitaloka Pahlawan Revolusi Ahmad Yani (Jakarta Pusat).

Proses pengumpulan data dilaku-kan melalui tiga cara yaitu studi literatur, observasi, dan wawancara mendalam. Studi literatur dilakukan dengan cara mengumpulkan data-data terkait mengenai museum tokoh pahlawan di Jakarta di antaranya adalah Museum Fatahillah, Museum M.H. Thamrin, Museum Jenderal Besar Dr. A.H Nasution, dan Museum Sasmitaloka Pahlawan Revolusi Ahmad Yani. Sebagai sumber literatur utama dalam pengumpulan data objek penelitian, Literatur yang digunakan terdiri dari beberapa buku, tesis, skripsi, dokumen online, maupun artikel surat kabar sebagai sumber informasi mengenai museum tokoh pahlawan di Jakarta.

Observasi merupakan teknik pengumpulan data dengan cara melaku-kan pengamatan tentang keadaan yang ada di lapangan. Adapun observasi dimulai pada bulan Juli 2017 sampai bulan Agustus 2018 dengan mengunjungi museum tokoh pahlawan di Jakarta seperti Museum Fatahillah, Museum M.H. Thamrin, Museum Jenderal Besar Dr. A.H Nasution, dan Museum Sasmitaloka Pahlawan Revolusi Ahmad Yani. Observasi ini dilakukan dengan tujuan agar dapat melihat dan mengamati kondisi museum tokoh pahlawan di Jakarta sebagai acuan dalam perancangan infografis serta mengamati perilaku dan demografi pengunjung sebagai acuan dalam penentuan target sasaran.

Wawancara dilakukan agar data yang diperoleh melalui observasi dapat lebih diperdalam. Data yang dicari dalam penelitian ini didapatkan dari beberapa narasumber yang kompeten seperti pihak pengelola museum, sejarawan, dan tour guide yang ada. Penelitian ini memiliki tiga narasumber yaitu Asep Kambali selaku sejarawan dan pemerhati museum sekaligus pendiri Komunitas Historia Indonesia (KHI), Untung Supardi selaku pihak pengelola Museum M.H. Thamrin, dan Wawan Sutrisno sebagai pemandu Museum Sasmitaloka Ahmad Yani.

Infografis sebagai sebuah representasi visual informasi yang meng-gunakan isyaratisyarat visual untuk mengkomunikasikan informasi, harus disampaikan secara komprehensif dan mudah dimengerti (Lankow, dkk, 2014: 22). Proses pembuatan infografis biasa disebut dengan beberapa istilah yang berbeda seperti data visualization, information design, dan information architecture. Dalam prosesnya, beberapa elemen desain komunikasi visual yang harus diperhatikan meliputi pemilihan huruf, pemilihan gaya visual untuk mengilustrasikan data, dan pemilihan warna.

Dalam infografis, gaya visual dalam ilustrasi dipergunakan untuk menyajikan anatomi sebuah benda secara estetis agar rancangan infografis menjadi lebih mengesankan (Inigopatria, 2014). Sebagai media visualisasi data yang komprehensif dan mudah dimengerti, pemilihan huruf dalam infografis menjadi penting untuk diperhatikan. Dalam pemilihan huruf, perlu diperhatikan dua unsur sebagai syarat karya tipografi yang baik yaitu Legibility atau kemudahan mata mengenali bentuk huruf dan Readability atau keterbacaan huruf (Anggraini \& Nathalia, 2014: 54). Begitu pula dalam pemilihan warna yang merupakan unsur penting dalam obyek desain. Terkait proses perancangan infografis, dalam menampilkan citra yang tepat, menyampaikan pesan, atau membedakan sifat secara jelas, kombinasi warna yang digunakan dengan baik akan memberikan dampak yang baik pula (Soewignjo, 2013: 43).

Konsep dasar perancangan dari infografis museum tokoh pahlawan di Jakarta sebagai museum arkeologi dan sejarah tidak lepas dari khalayak yang akan dituju dari perancangan infografis ini. Implikasi utama adanya infografis museum tokoh pahlawan di Jakarta adalah adanya media pengenalan mengenai museum tokoh pahlawan di Jakarta kepada masyarakat 
luas khusus-nya masyarakat kota Jakarta. Oleh karena itu, perlu ditetapkan analisis khalayak yang tepat sebagai acuan dari konsep dasar perancangan infografis.

Segmentasi geografis dari infografis ini adalah kota Jakarta. Hal ini dikarenakan masih banyak masyarakat kota Jakarta itu sendiri yang belum mengetahui keberadaan museummuseum yang ada di Jakarta, khususnya museum tokoh pahlawan. Namun, tidak menutup kemungkinan infografis ini juga dinikmati untuk masyarakat yang berada di wilayah penyangga ibukota seperti Bogor, Depok, Tangerang, dan Bekasi, agar tertarik untuk mengetahui dan mengunjungi museum tokoh pahlawan di Jakarta sebagai wisata edukasi yang terjangkau. Sementara itu, segmentasi demografis dari infografis ini adalah remaja laki-laki dan perempuan golongan menengah dengan usia 15-20 tahun. Berdasarkan hasil observasi, sangat sedikit kunjungan ke museum tokoh pahlawan dilakukan oleh segmentasi usia tersebut. Remaja di usia tersebut cenderung lebih menyukai berkunjung ke tempat-tempat yang lebih menarik dikarenakan adanya pemikiran bahwa museum merupakan tempat yang menyeramkan. Psikografis dari remaja laki-laki dan perempuan dilihat berdasarkan gaya hidup mereka yang senang berjalan-jalan dan tertarik akan sesuatu yang artistik.

Infografis yang akan dibuat khususnya menargetkan remaja usia 15-20 tahun yang tinggal di wilayah Jakarta dan sekitarnya serta tertarik akan sesuatu yang artistik. Oleh karena itu, dalam perancangan ini, positioning yang digunakan adalah pengenalan museum tokoh pahlawan sebagai museum arkeologi dan sejarah yang memiliki koleksi-koleksi yang unik. Perancangan ini membantu para remaja agar lebih mengetahui keunikan museum tokoh pahlawan di Jakarta agar dapat menarik minat mereka untuk berkunjung dan memperkaya ilmu pengetahuan terkait benda-benda peninggalan sejarah.

\section{HASIL DAN PEMBAHASAN}

Perancangan infografis dengan judul "Museum Tokoh Pahlawan Jakarta" ini akan menghasilkan infografis yang memiliki durasi kurang lebih 4 menit dengan frame size 16:9 dan format luaran berupa video HD (High Definition) dengan resolusi 1920 x 1080 px. Alur informasi dalam infografis akan dibagi menjadi tiga segmen yaitu segmen pembuka, segmen isi, dan segmen penutup. Segmen pembuka berisikan judul dan pembahasan pengertian museum, fungsi dan tugas museum, jumlah museum di Jakarta, dan jenis-jenis museum. Segmen isi berisikan tentang empat museum tokoh pahlawan Jakarta yakni museum Fatahillah, museum M.H. Thamrin, museum Jenderal Besar Dr. A.H. Nasution, dan museum Sasmitaloka Pahlawan Revolusi Ahmad Yani. Dalam segmen ini dibahas mengenai sejarah awal berdirinya museum, data fisik museum, biografi singkat tokoh pahlawan, dan koleksi yang dipamerkan di museum tersebut. Segmen penutup berisikan tentang pesan berupa kata bijak dari sang proklamator bangsa yaitu Ir. Soekarno, "Bangsa yang besar adalah bangsa yang menghargai jasa para pahlawannya". Kemudian infografis diakhiri dengan adanya logo Dinas Pariwisata Provinsi DKI Jakarta.

Penempatan media infografis museum tokoh pahlawan Jakarta ini adalah di pusat-pusat keramaian dan sesuai dengan target audiens yaitu di videotron, pada televisi di dalam gerbong Commuter Line, dan pada televisi di dalam halte Busway. Media infografis museum tokoh pahlawan Jakarta juga akan diberikan kepada Dinas Pariwisata dan Kebudayaan Provinsi DKI Jakarta, serta Unit Pengelola Museum Kesejarahaan Jakarta sebagai media informasi mengenai museum tokoh pahlawan Jakarta dan akan disebarluas-kan melalui media sosial seperti Facebook, Instagram, dan Youtube. Penempatan-penempatan media tersebut dipilih agar audiens dapat dengan mudah mengetahui dan menerima informasi mengenai museum tokoh pahlawan di Jakarta. 

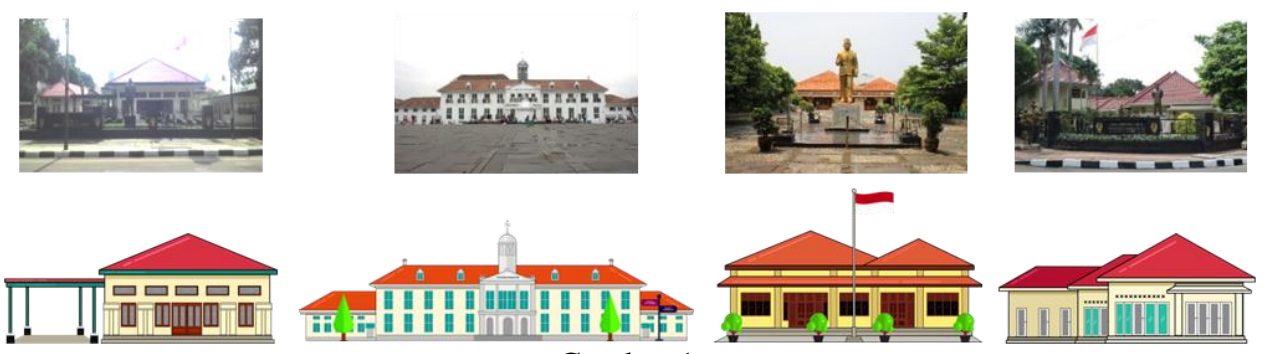

Gambar 1.

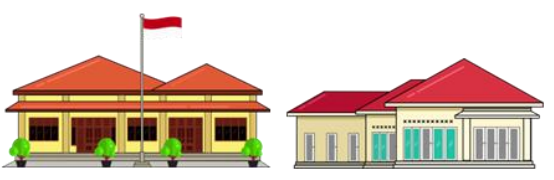

Ikon Museum Pahlawan Jakarta

(Ki-Ka): Museum A.H. Nasution, Museum Fatahillah, Museum M.H. Thamrin, Museum Ahmad Yani

Gaya visual yang digunakan dalam perancangan infografis museum tokoh pahlawan Jakarta adalah gaya visual flat design. Pemilihan gaya visual tersebut dikarenakan bentuknya yang sederhana dan mudah dimengerti. Selain itu akan banyak ikon yang mendukung konten dalam tiap scene yang ditampilkan agar audiens lebih mudah memahami informasi yang disajikan. Ikon museum yang dirancang untuk infografis ini dapat dilihat pada gambar 1 .

Selain itu, beberapa ikon juga dirancang untuk memunculkan ruangan-ruangan dan koleksi-koleksi yang ada di museum. Perancangan ikon ditata ke dalam layar untuk memberikan kesan seakan-akan audiens sedang berada di dalam museum dan berjalan menyusuri ruangan museum. Tampilan animasi menggunakan efek panning untuk mendukung suasana yang ingin dicapai. Contoh perancangan ikon ini dapat dilihat di gambar 2.

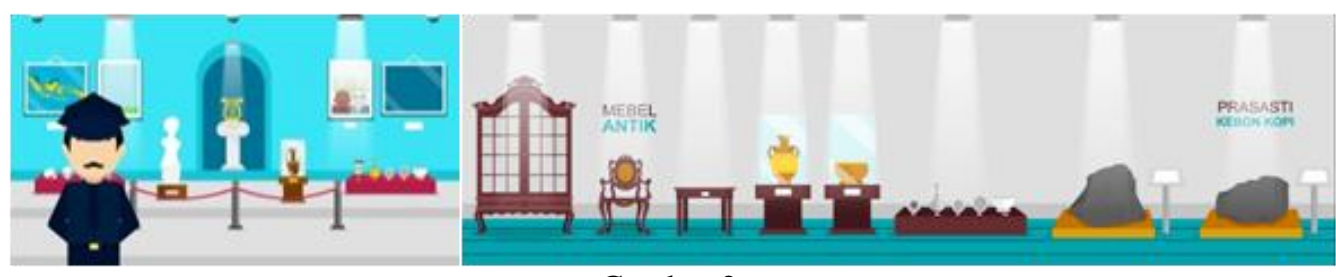

Gambar 2.

Ikon ruangan dan tata letak ikon koleksi-koleksi museum pada layar

Tipografi yang digunakan pada infografis ini adalah jenis huruf sans serif yaitu jenis huruf yang tidak memiliki kaki dan tebal tipis stroke-nya umumnya sama. Huruf jenis ini dipilih dalam perancangan infografis museum tokoh pahlawan Jakarta karena terkesan lebih sederhana, tegas, modern dan memiliki tingkat keterbacaan yang cukup tinggi. Dalam infografis museum tokoh pahlawan Jakarta terdapat dua typeface yang digunakan, yaitu Jersey M54 yang digunakan pada judul dan Arial yang digunakan sebagai informasi yang ada di dalam infografis. Penggunaan typeface Jersey M54 sebagai pada judul infografis dapat dilihat pada gambar 3.

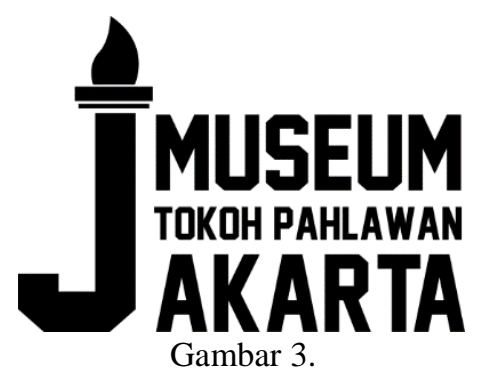

Apikasi typeface Jersey M5 pada judul infografis 
Warna yang digunakan pada perancangan infografis museum tokoh pahlawan adalah perpaduan antara warna panas dan dingin. Di antaranya adalah warna merah, warna kuning, dan warna biru. Warna merah digunakan dalam penggambaran ikon koleksi-koleksi museum untuk menampilkan warna yang kontras dan dapat menarik perhatian. Warna kuning digunakan sebagai warna dari teks isi infografis karena sifatnya yang hangat dan memberikan kesan optimis. Warna biru dipilih sebagai warna latar karena sifatnya yang dingin dan memberikan kesan ketenangan sehingga diharapkan mampu meminimalisir pe-mikiran bahwa museum merupakan tempat yang menakutkan. Dari warna-warna yang telah di pilih, diharapkan infografis ini mampu menarik minat masyarakat untuk berkunjung ke museum, khususnya museum tokoh pahlawan. Skema warna dan aplikasinya dalam infografis dapat dilihat pada gambar 4.

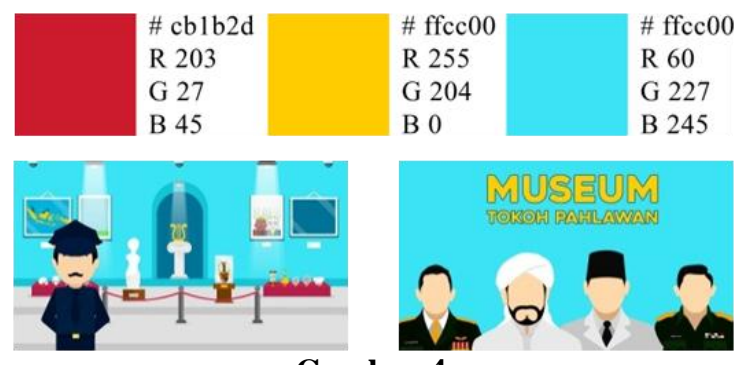

Gambar 4.

Skema warna dan aplikasinya dalam infografis

Selain merancang infografis dinamis, terdapat juga media pendukung yang dirancang berkaitan dengan infografis museum tokoh pahlawan Jakarta. Media pendukung tersebut dirancang sebagai bagian dari sosialisasi media utama yang dibuat. Media pendukung yang dibuat di antaranya, poster berupa infografis statis ukuran A3 $(29,7 \mathrm{~cm} \times 42 \mathrm{~cm})$ dan booklet mengenai museum tokoh pahlawan di Jakarta dengan ukuran A5 $(14,8 \mathrm{~cm} \times 21 \mathrm{~cm})$. Desain poster dan booklet dapat dilihat pada gambar 5 dan gambar 6 .

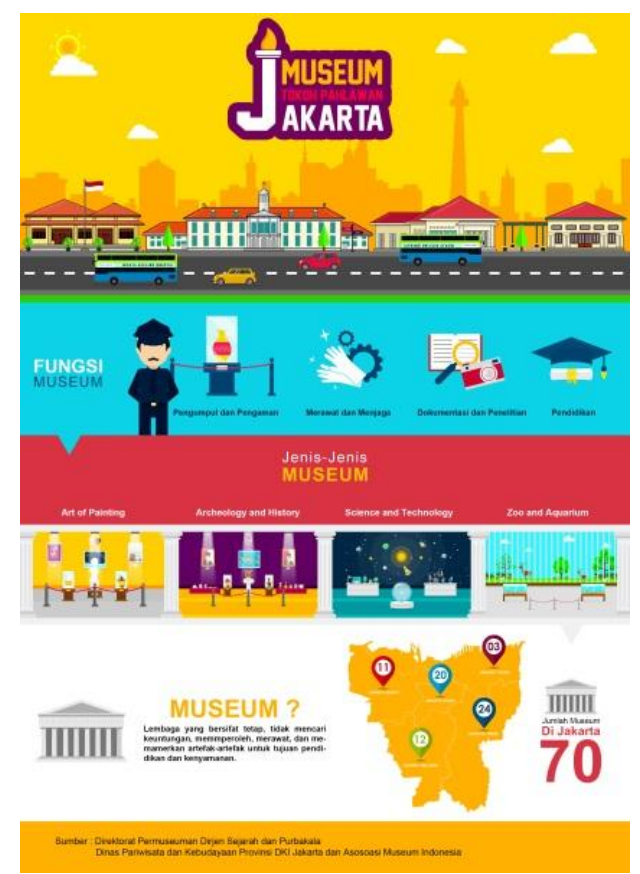

Gambar 5.

Desain poster berupa infografis statis 


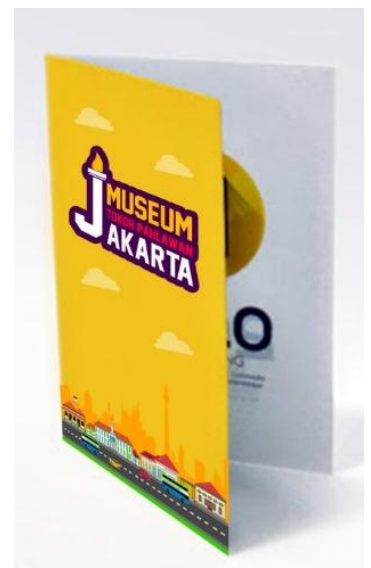

Gambar 6.

Desain booklet museum pahlawan di Jakarta

Dengan adanya infografis dinamis yang berisi sejarah dan hal-hal menarik yang ada di museum tokoh pahlawan tersebut, serta media pendukung berupa poster dan booklet, diharapkan masyarakat kota Jakarta, khususnya kalangan remaja dapat lebih mengetahui akan keberadaan museum tokoh pahlawan di Jakarta. Perancangan ini juga memiliki implikasi berupa adanya penyebaran informasi melalui media digital yang mudah dijangkau oleh para remaja melalu gawai yang mereka miliki. Keberadaan infografis ini diharapkan dapat menarik minat remaja untuk berkunjung ke museum tokoh pahlawan di Jakarta sebagai tujuan wisata arkeologis dan sejarah.

\section{SIMPULAN}

Berdasarkan hasil penelitian yang telah dilakukan, dapat disimpulkan bahwa terdapat kekurangan minat pada masyarakat, terutama remaja untuk mengunjungi wisata sejarah seperti museum, dikarenakan masyarakat masih belum mengetahui arti pentingnya keberadaan museum sebagai destinasi wisata dan edukasi. Selain itu, masyarakat menganggap museum sebagai tempat yang membosankan yang hanya menyimpan benda-benda kuno dan terkesan menyeramkan. Untuk menjawab tantangan dalam mengubah pemikiran tersebut, infografis ini muncul dengan skema warna yang disesuaikan agar dapat menampilkan kesan segar dari museum sehingga menghilangkan kesan suram dan gelap sebagai citra yang melekat di masyarakat, terutama remaja.

Kurangnya minta masyarakat juga disebabkan karena kurangnya media informasi yang menarik yang mudah dijangkau dengan memanfaatkan kemajuan teknologi informasi saat ini. Bentuk upaya dalam menyelesaikan masalah tersebut adalah melalui perancangan infografis dinamis museum tokoh pahlawan di Jakarta yang mudah disebarkan melalui media-media sosial. Desain yang diterapkan pada perancangan infografis museum tokoh pahlawan di Jakarta menerapkan konsep flat design, dengan pemilihan warna-warna yang memiliki kesan ceria, hangat, dan nyaman serta penggunaan jenis huruf yang memiliki kesan sederhana, modern, dan memiliki tingkat keterbacaan yang cukup baik sehingga pesan atau informasi yang disampaikan mengenai museum tokoh pahlawan di Jakarta lebih jelas dan mudah untuk dipahami oleh masyarakat, terutama para remaja.

Perancangan infografis merupakan salah satu upaya pelestarian warisan sejarah dan peninggalan budaya berupa museum sebagai wadah koleksi artefak yang kaya akan nilai-nilai yang dapat dipelajari. Untuk itulah, remaja menjadi target utama dari perancangan infografis 
ini sebagai penerus bangsa yang dapat menjaga wawasan dan nilai-nilai yang terhimpun dalam museum tokoh pahlawan beserta sejarahnya. Oleh karena itu, perancangan media yang menarik dan efektif dalam menyampai-kan informasi seperti infografis dinamis cukup dibutuhkan dalam memperkenal-kan kembali objek-objek wisata yang memiliki citra yang kurang menarik di mata masyarakat seperti museum tokoh pahlawan di Jakarta.

\section{DAFTAR PUSTAKA}

Anggraini, S. \& Nathalia, K. (2014). Desain Komunikasi Visual Dasar-Dasar Panduan Untuk Pemula. Bandung: Nuansa Cendekia.

BPS Provinsi DKI Jakarta. (2016). Jakarta Dalam Angka. Jakarta: BPS Provinsi DKI Jakarta.

Destha, S. M. (2016). Perancangan Buku foto Museum Kepahlawanan Jakarta Sebagai Wisata Edukasi Sejarah. Skripsi. Fakultas Bahasa dan Seni. Universitas Indraprasta PGRI.

Dimyati, E. (2010). 47 Museum Jakarta. Jakarta: PT Gramedia Pustaka Utama.

Inigopatria, S. (2014). Indonesia dalam Infografis. Jakarta: Kompas 2014.

Lankow, J. dkk. (2014). Infografis Kedahsyatan Cara Bercerita Visual. Jakarta: PT Gramedia Pustaka Utama.

Pemda DKI Jakarta. (2004). Lintasan Sejarah Jakarta. Jakarta: Dinas Kebudayaan dan Permuseuman Provinsi DKI Jakarta.

Soewignjo, S. (2013). Seni Mengatur Komposisi Warna Digital. Yogyakarta: Taka Publisher 